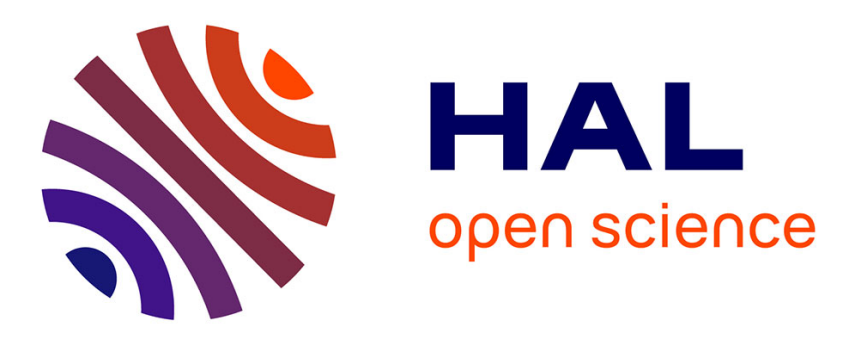

\title{
A Simplified Control Oriented Model Of an Open Cathode PEM Fuel Cell
}

Shanal S Kumar, Maurizio Cirrincione, Vincent Léchappé, Krishnil Ram, Ali Mohammadi

\section{- To cite this version:}

Shanal S Kumar, Maurizio Cirrincione, Vincent Léchappé, Krishnil Ram, Ali Mohammadi. A Simplified Control Oriented Model Of an Open Cathode PEM Fuel Cell. ECCE-Asia, May 2021, Singapore, Singapore. pp.2415-2420, 10.1109/ECCE-Asia49820.2021.9479098 . hal-03353498

\section{HAL Id: hal-03353498 https://hal.science/hal-03353498}

Submitted on 24 Sep 2021

HAL is a multi-disciplinary open access archive for the deposit and dissemination of scientific research documents, whether they are published or not. The documents may come from teaching and research institutions in France or abroad, or from public or private research centers.
L'archive ouverte pluridisciplinaire HAL, est destinée au dépôt et à la diffusion de documents scientifiques de niveau recherche, publiés ou non, émanant des établissements d'enseignement et de recherche français ou étrangers, des laboratoires publics ou privés. 


\section{A Simplified Control Oriented Model Of an Open Cathode PEM Fuel Cell}

\author{
Shanal S Kumar \\ University of the South Pacific \\ Suva, Fiji \\ s11121467@student.usp.ac.fj \\ Krishnil R Ram \\ University of the South Pacific \\ Suva, Fiji \\ krishnil.ram@usp.ac.fj
}

\author{
Maurizio Cirrincione \\ University of the South Pacific \\ Suva, Fiji \\ maurizio.cirrincione@usp.ac.fj \\ Ali Mohammadi \\ University of the South Pacific \\ Suva, Fiji \\ ali.mohamamdi@usp.ac.fj
}

\author{
Vincent Léchappé \\ Univ Lyon, INSA Lyon, Université \\ Claude Bernard Lyon 1, \\ Ecole Centrale de Lyon, CNRS, \\ Ampère, \\ UMR5505, 69621 Villeurbanne, France \\ vincent.lechappe@insa-lyon.fr
}

\begin{abstract}
- the paper presents a simplified nonlinear model for an open cathode Proton Exchange Membrane Fuel Cell (PEMFC) and its control using two different control strategies. The model presented uses only three state variables and is therefore easy to model and control. The mass flow of oxygen, hydrogen and water were taken to be the key dynamics in the system. The unknown parameters were estimated using the experimental data of a $1.2 \mathrm{~kW}$ PEMFC. The model showed good agreement with experimental results. With the objective of maintaining a fixed oxygen excess ratio - a Proportional Integral (PI) Control and a Sliding Mode Control (SMC) scheme were applied to the system model. This paper compares the results of a simple PEMFC model without controller, with a PI controller and a Sliding Mode controller. The SMC performs better in terms of maintaining a fixed oxygen excess ratio of 2 . The results also show that the simplified model has good use at an early design stage for systems using PEMFC and also for learning purposes.
\end{abstract}

Keywords—fuel cell, hydrogen, dynamic model, sliding mode, open cathode.

\section{INTRODUCTION}

Fuel Cells offer an emission-free means of energy conversion in stationary power applications as well as in the transport sector. Several types of Fuel Cells such as Solid Oxide Fuel Cells (SOFC), Direct Methanol Fuel Cells (DMFC) and Polymer Electrolyte Membrane (or Proton Exchange Membrane) (PEM) Fuel Cells dominate the fuel cell market [1]. This paper focuses mainly on PEM Fuel Cells. In general, fuel cells have an anode and a cathode side. Hydrogen enters through the anode while oxygen enters through the cathode. The reactions of the two gases allow for the generation of electrical energy across the Fuel Cell terminals. With only water and heat as by-products, the PEM Fuel Cell (PEMFC) has no carbon dioxide emission. Open Cathode Fuel Cells do not use supply manifolds fed by compressors and humidifiers hence have much less patristic losses and have fewer components to maintain. This has made open cathode PEMFC a common choice, especially in transport sectors. In PEMFC, fans are used to force air through open cathodes to channel the oxygen onto the Membrane Electrode Assembly (MEA). An open cathode PEMFC has lower costs due to fewer components. The loss of auxiliary equipment requires a better control of the operating parameters for optimal operation. A key control objective to ensure longer life of PEMFC aims to avoid oxygen starvation during operation. Oxygen is normally obtained from atmospheric air, which is pulled into the PEMFC anode using axial fans. In case of oxygen starvation, the Fuel Cell suffers from degradation and would not be able to supply the required power [2], [3]. For this reason, an excess of oxygen in the anode is necessary to avoid starvation.

Several works have proposed dynamic models to control the oxygen excess ratio in PEMFC [4], [5]. The models vary in their focus on different dynamics in the PEMFC system. Reference[6] presents PEMFC modelling for controlling a large PEMFC with a compressor used to force humidified air into the cathode side. Another paper [7] has focused on the pressure balance to effectively model the dynamic effects in PEMFC to improve internal designs and external controller designs. PEMFC emulators with dynamic models have also been proposed as a cheap alternative for hardware testing [8]. Detailed models are very useful to observe all the different variables in the system, but these models are difficult to implement and computationally cumbersome. Time delays in PEMFC response arise from the delays in the electrochemical reactions as well.

The present work proposes a much simplified PEMFC model which focuses mainly on the reactant behavior and power output. With the single control objective of maintaining a desired oxygen excess ratio, the present control model is a balance between accuracy and response time of the PEMFC to the demand load profile. Several control strategies can be applied to PEMFC. Classical feedback with Proportional Integral (PI) is one of the most common type of control used in fuel cells performance [9] . Classical PI or PID control with feedback is generally used to prevent oxygen starvation due to its simplicity and low cost [10], [11]. Sliding mode control (SMC) is a technique derived from the variable structure control and it was initially studied by Utkin [12]. SMC is a simple procedure and a robust controller for linear and nonlinear systems. Additionally, it has obtained good performance in controlling chemicals processes [13]. This paper first proposes a simplified PEMFC model using three state variables and then compares the results of PI and SMC control strategies on the simplified model. 


\section{MATHEMATICAL MODEL}

\section{A. Stoichiometry}

The stoichiometry of the combined PEMFC reaction yields the molar ratios of reactant gases and products. The chemical reaction in the PEMFC is caused by hydrogen and oxygen gases and produces electricity, heat and water. The reaction is stated as:

$$
2 \mathrm{H}_{2}+\mathrm{O}_{2} \Leftrightarrow 2 \mathrm{H}_{2} \mathrm{O}
$$

From the above reaction, 2 moles of hydrogen gas needs to react with 1 mole of oxygen gas to produce 2 moles of water. If molar masses are considered, then $4 \mathrm{~g}$ of hydrogen reacts with $32 \mathrm{~g}$ of oxygen gas to form $36 \mathrm{~g}$ of water. This gives a hydrogen to oxygen mass ratio of 1:8 for a complete reaction. The current generated during the PEMFC operation is closely linked to the moles of each gas consumed in the reaction: The stack current is given by:

$$
I=\frac{m_{O_{2}} 4 F}{M_{O_{2}}}=\frac{m_{H_{2}} 2 F}{M_{H_{2}}}
$$

where $m_{\mathrm{O}_{2}}$ and $m_{\mathrm{H}_{2}}$ are the masses of the reactant gases in grams, $M_{\mathrm{O}_{2}}$ and $M_{\mathrm{H}_{2}}$ are the molar masses of oxygen and hydrogen gases, respectively and $\mathrm{F}$ is the Faraday constant given in $\mathrm{C} / \mathrm{mol}$.

\section{B. Oxygen mass flow}

At the cathode, side air is forced into the cathode channels using axial fans. The fans also provide cooling to the PEMFC. The following equation can be obtained by applying the mass conservation at the cathode side, [3]:

$$
\dot{m}_{0_{2}}=\dot{m}_{0_{2}, \text { in }}-\dot{m}_{0_{2}, \text { used }}-\dot{m}_{0_{2}, \text { out }}=\dot{x}_{1}
$$

By taking oxygen mass $m_{0_{2}}$ is a state variable $x_{1}$ and noting the load current $I$ as the input $u$, then equation 2 can be rewritten as:

$$
\begin{aligned}
& \dot{m}_{0_{2}, \text { in }}=\lambda_{O_{2}} y_{o 2, c a}\left(1-\frac{P_{s a t} \emptyset_{c}}{K p u}\right) K f u \\
& \dot{m}_{0_{2}, \text { used }}=\frac{M_{O 2} \text { un }}{4 F} \\
& \dot{m}_{0_{2}, \text { out }}=k_{c, \text { out }} \dot{m}_{0_{2}}
\end{aligned}
$$

$\dot{x}_{1}=\lambda_{O_{2}} y_{o 2, c a}\left(1-\frac{P_{s a t} \psi_{c}}{k_{p} u}\right) k_{f} u-\frac{M_{O 2} u n}{4 F}-k_{c, o u t} x_{1}$

where $\lambda_{\mathrm{O}_{2}}$ represents the oxygen excess ratio which is generally accepted to be around 2 . The molar fraction of oxygen in the incoming air is denoted by $y_{o 2, c a}$, while $P_{s a t}$ is the saturation pressure of the water at cathode side. The relative humidity is indicated by $\psi_{c}$. The inlet side pressure is assumed to be proportional to the input current linearly with the factor $k_{p}$ as the gradient. The fan conditions are represented as constant $k_{f}$. The fan increases its speed based on an increase in load current, and the constants are estimated using characteristic fan curves. Similarly $k_{c, \text { out }}$ represents the effect of the outlet conditions. The constants were estimated empirically by comparing flow rate graphs.

\section{Hydrogen mass flow}

Similar to the cathode side gas dynamics, the hydrogen gas dynamics can be written by using the net flow of hydrogen where the load current is taken as the input.

$$
\dot{x}_{2}=\left(1-\frac{P v_{a}}{P a}\right) k_{v} u-\frac{M_{H 2} u n}{2 F}-k_{a, o u t} x_{2}
$$

At the cathode $P v_{a}$ is taken as the partial pressure of water vapor while $P a$ is the pressure of the anode. A valve constant $k_{v}$ is used to estimate the response of the valve to input current. The outlet flow conditions that affect the mass of hydrogen leaving the anode is taken as $k_{a, \text { out }}$.

\section{Water mass flow}

Most of the water forms at the cathode and this moisture passes through the layers to reach the anode side. The anode water content is essential for this simplified model. It can be assumed that is the water is less compared to the cathode side, and this can be combined directly into the cathode hydration model. The hydration of the membranes also plays an important role in power production and polarization curves.

$$
\begin{aligned}
\dot{x}_{3}= & \frac{m_{H_{2} O} O}{P_{c a} \cdot K_{w 1}} \cdot m_{c a}+K_{w 2} U+\left(K_{w 3} \cdot U-K_{w 4}\right) \cdot K_{w 5}- \\
& \frac{m_{H_{2} O}}{U \cdot K_{w 1} \cdot K_{w 6}} \cdot m_{c a, o u t} K_{w 7}
\end{aligned}
$$

where $K_{w 1}, K_{w 2}, K_{w 3}, K_{w 4}, K_{w 5}, K_{w 6}, K_{w 7}$ are constants that have been derived empirically. The flow rate of water is taken as $\dot{x}_{3}, m_{c a}$ is the mass at cathode inlet and $m_{\text {ca.out }}$ is the mass at cathode outlet. While the hydration equation is part of the simplified model, it does not affect the control of the oxygen excess ratio.

\section{E. Electrical model and voltage losses}

The voltage (generated from the electrochemical) potential reaction is determined by the Gibbs Free energy equations [6]. Since the reaction takes place across the surface area $A_{F C}$ of the MEA, the current produced is proportional to the area of the MEA or commonly stated as the fuel cell area. The current density $i$ is used in determination of voltage losses in the PEMFC:

$$
i=\frac{I}{A_{F C}}
$$

where $A_{F C}$ is given in $\left[\mathrm{cm}^{2]}\right.$ and the stack current $I$ in [A]. The pressures of hydrogen and oxygen gases are found by using the ideal gas equation. The mass corresponds to the values found by integrating hydrogen and oxygen flow rate equations. 


$$
\begin{aligned}
& p_{O_{2}}=\frac{m_{O_{2} R_{O_{2}} T}}{V_{c a}} \\
& p_{H_{2}}=\frac{m_{H_{2} R_{H_{2}} T}}{V_{a n}}
\end{aligned}
$$

The Nernst voltage or the theoretical voltage potential the PEMFC can develop at a certain pressure of hydrogen and oxygen is given by:

$$
\begin{aligned}
\mathrm{E}= & 1.229-0.85 \times 10^{-3}(T-298.15)+4.3085 \times \\
& 10^{-5} T\left[\ln \left(p_{\mathrm{H}_{2}}\right)+\frac{1}{2} \ln \left(p_{\mathrm{O}_{2}}\right)\right]
\end{aligned}
$$

While the Nernst voltage provides the theoretical maximum voltage, there are several voltage losses which occur in the PEMFC to reduce the actual output voltage for the cells:

$$
v_{f c}=E-\left(v_{a c t}+v_{o h m}+v_{\text {conc }}\right)
$$

These losses arise from three areas - activation losses, ohmic losses and concentration losses. The activation losses arise due to energy requirements for breaking the bonds and the sluggish rate of reactions at the electrode surface [20].

$$
v_{a c t}=v_{0}+v_{a}\left(1-e^{-c_{1} i}\right)
$$

where $v_{a}, v_{o}$ and $c_{l}$ are constants that need to be estimated as shown in [14]. The resistance of electron flow for conducting electrodes and the resistance of ion flow for the membrane results in ohmic losses:

$$
v_{o h m}=i R_{o h m}
$$

where $R_{\text {ohm }}$ is the internal resistance of the PEMFC. The concentration voltage losses $v_{\text {conc }}$ arise due to concentration gradients as the reactants get used up at the cell surfaces and the slow transport of reactants to and from the reaction sites. This can be computed as:

$$
v_{\text {conc }}=i\left(c_{2} \frac{i}{i_{\max }}\right)^{c_{3}}
$$

The reactant flow dynamics in the PEMFC are used in equation 9 to estimate the total theoretical voltage that can be generated by each cell. The reactant gas flow changes in line with the demand current, which can be assumed to be the only input into the system.

\section{F. Model Control Scheme}

Two different control topologies are tested on the simplified model. The primary control objective is to ensure that the oxygen excess ratio is maintained at 2 . Firstly, a PI like control scheme is applied as shown in Fig 1:

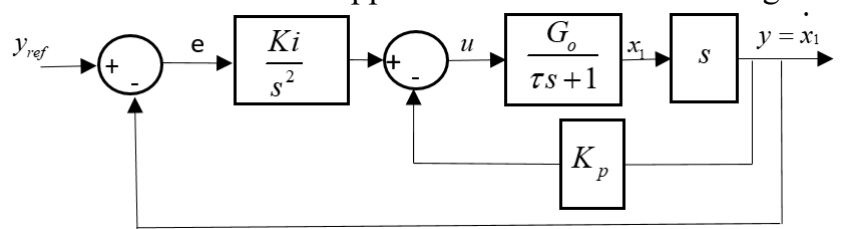

Fig. 1 PI-like Controller scheme for maintaining oxygen excess ratio. where $G_{o}=3.65 e^{-4}$ and $\tau=100$ are obtained from equation(6). From the block diagram of Fig 1, the following equation is derived:

$\frac{y}{y_{\text {ref }}}=\frac{2}{\frac{\tau+K_{p} G_{O}}{K_{i} G_{O}} s^{2}+\frac{1}{K_{i} G_{O}} s+1}=\frac{2}{\frac{1}{\omega_{C L}^{2}} s^{2}+\frac{2 \varepsilon_{C L}}{\omega_{C L}} s+1}$

This transfer function has a gain equal to 2 , so the oxygen excess ratio $\frac{\dot{x}_{1}}{\dot{x}_{1 \text { ref }}}=\lambda_{O_{2}}$ will be equal to 2 . In addition, the closed loop dynamics can be tuned by choosing proper gains $K_{p}$ and $K_{i}$. For desired closed specifications $\omega_{C L}$ and $\varepsilon_{C L}$ :

$$
\begin{aligned}
& K i=\frac{\omega_{C L}}{2 G_{o} \varepsilon_{C L}} \\
& K_{p}=\frac{1}{G_{o}}\left(\frac{K_{i} G_{O}}{\omega_{C L}^{2}}-\tau\right)
\end{aligned}
$$

Taking $\varepsilon_{C L}=1$ and $\omega_{C L}=0.1$ gives $K i=13.6054$ and $K_{p}=-1.3605 \times 10^{5}$. Given that the system model has been simplified, a robust control strategy needs to be adopted to ensure optimum control despite losing some details in the model. For this reason, a sliding mode control scheme is applied and then compared with a PI control.

The sliding model control equations can be derived from the state equations. Solving for all constants and assuming $y=v$ for the auxiliary controller, thus

$$
u=\frac{1}{\lambda_{O_{2}} c 1-c 3}\left(\lambda_{o_{2}} c_{2}+x_{1}+v\right)
$$

is obtained from equation (6). The first-order sliding mode control topology was developed with the objective of controlling the oxygen excess ratio. The following auxiliary control equation can be stated as:

$$
v=k_{1} y+k_{2} y_{r e f}+\dot{y}+k_{3} \operatorname{sign}(e)
$$

where $k_{1}, k_{2}$ and $k_{3}$ are gains that were tuned using a Lyapunov analysis. Defining the Lyapunov function candidate as:

$$
V=\frac{1}{2} e^{2}
$$

where $e=y_{\text {ref }}-y$ is the sliding surface and taking its time derivative gives:

$$
\begin{gathered}
\dot{V}=\dot{e} e \\
\dot{V}=-\dot{y} e \\
\dot{V}=\left[\left(1-k_{1}\right) y-k_{2} y_{r e f}-k_{3} \operatorname{sign}(e)\right] e
\end{gathered}
$$

In particular choosing $k_{2}=1-k_{1}$ leads to:

$$
\dot{V}=\left(1-k_{1}\right) e^{2}-k_{3} \operatorname{sign}(e) e
$$

Setting $k_{1}>1$, the following inequality can be obtained

$$
\dot{V} \leq-k_{3} \sqrt{2} \sqrt{V}
$$

by which $V$ will reach zero in finite time or that $y$ will reach $y_{d}$ in finite time. The block diagram of the control scheme is shown in Fig.2. 


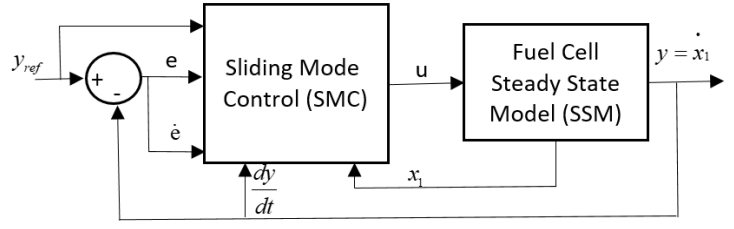

Fig. 2 Sliding Mode Control scheme for maintaining oxygen excess ratio.

The constants used in the model are given in the Table 1 below. Parameters for the electrical model are given in [14]:

TABle I CONSTANTS USED IN THE Model

\begin{tabular}{|c|c|}
\hline$M_{H 2}=2.016 \times 10^{-3} \mathrm{~kg} / \mathrm{mol}$ & $M_{O 2}=32 \times 10^{-3} \mathrm{~kg} / \mathrm{mol}$ \\
\hline$y_{o 2, c a}=0.21$ & $\lambda O_{2}=2$ \\
\hline$P_{\text {sat }}=3.17 \mathrm{kPa}$ & $n=42$ \\
\hline$T=300 \mathrm{~K}$ & $F=96,485 \mathrm{C} / \mathrm{mol}$ \\
\hline$K p=21 \mathrm{kPa}$ & $k_{c, \text { out }}=0.01$ \\
\hline$P a=600 \mathrm{kPa}$ & $k_{a, \text { out }}=1 \times 10^{-11}$ \\
\hline$K f=1.27 \times 10^{-5}$ & $\emptyset_{a}=1 \times 10^{-4}$ \\
\hline$K v=4.2 \times 10^{-7}$ & $\emptyset_{c}=0.7$ \\
\hline
\end{tabular}

\section{G. Experimental Setup}

A 1.2 kW Open Cathode PEMFC was loaded using a DC electronic load as shown in Fig 3. Data was collected from the PEMFC user interface module. A single ramp current load was programmed into the electronic load, starting at $2 \mathrm{~A}$ and ending at 60A. The PEMFC was not able to output a current lower than 2A. Voltage and current was logged in the Electronic load as well. The sampling rate in both cases are $2 \mathrm{~Hz}$.

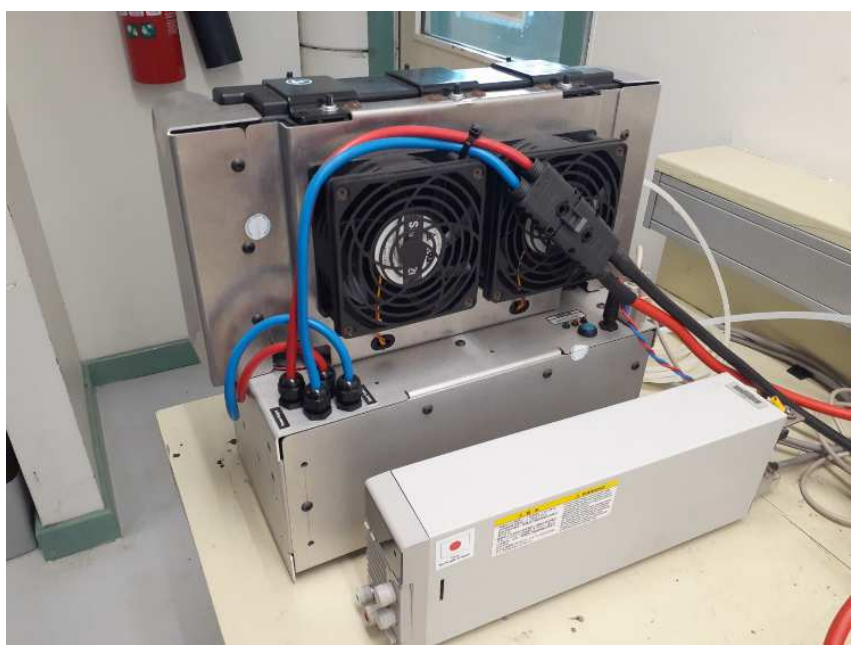

Fig. 3 The 1.2kW Fuel Cell setup.

\section{MODEL RESULTS AND VALIDATION}

Simulink model was run for 100 s and the resulting polarization curve was compared to the measured experimental data. The PEMFC used to gather the experimental results had 42 cells with maximum voltage reaching $0.9 \mathrm{~V}$ in each cell. The PEMFC area was $62 \mathrm{~cm}^{2}$ while its membrane thickness was $0.42 \mathrm{~mm}$. Parameter estimation was carried out using nonlinear least squares method. The parameter estimation details are stated in [14].

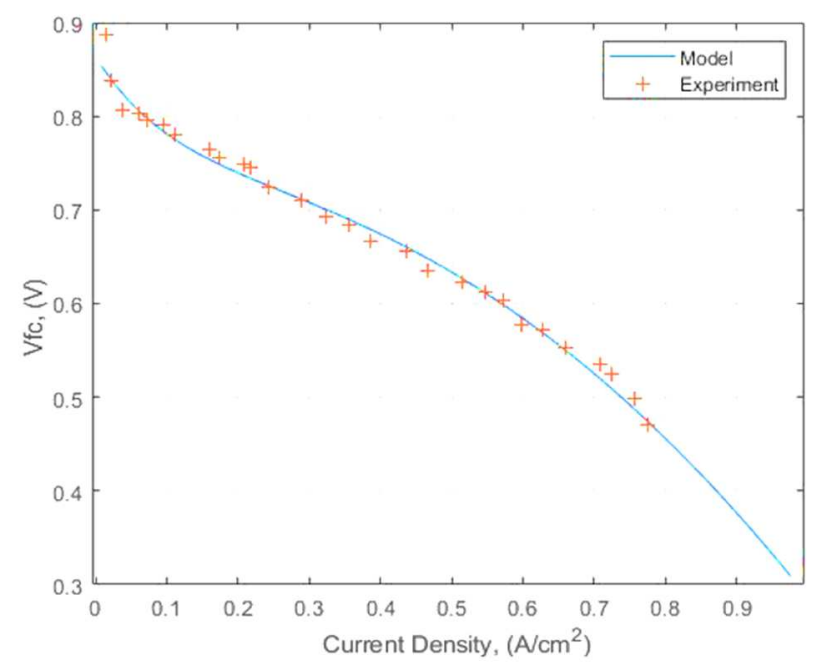

Fig. 4 Experimental and model results compared.

Generally, there is good agreement between the polarization curve estimated through the model and the results obtained through experiments. It is essential for a good PEMFC model to accurately predict the flow rate of gasses for changing load currents. A load profile was applied to the model and the change in flow rates of oxygen and hydrogen are shown in Fig 5.
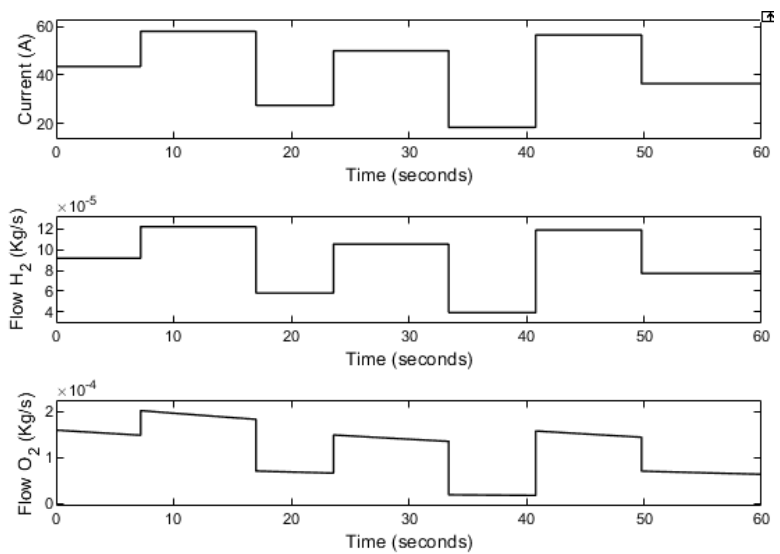

Fig. 5 Flow rate variation with respect to load current.

There is some delay in flow rate of hydrogen in the system when the load current changes abruptly. For oxygen the delays in following the load current is very high during load changes and even at constant current intervals - the flowrate is poorly maintained. The poor response of oxygen flow without a controller will not achieve the desired stoichiometry and results in power loss. Fig 6 shows how the oxygen excess ratio changes with time. It is noteworthy that between $30 \mathrm{~s}$ and $40 \mathrm{~s}$ the excess ratio drops below one. An excess ratio below one means that less oxygen is supplied than what is required to produce the load current. Not only does this result in power loss, but it also causes cell degradation. 

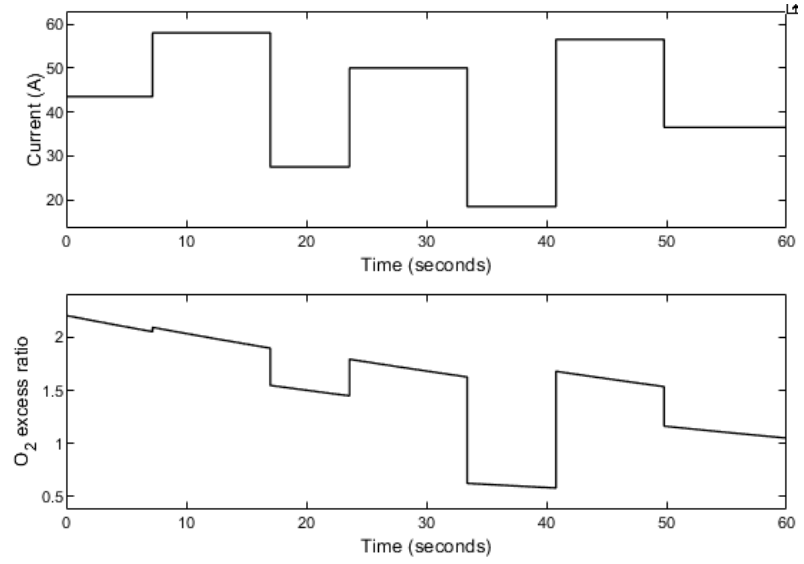

Fig. 6 The oxygen excess ratio without a controller.

For the PI controller the gains were tuned to be $K_{p}=$ $-1.3605 \mathrm{e} 5$ and $K i=13.6054$. The use of a PI controller improves the systems oxygen excess ratio and oxygen flow response. The results in Fig 7 clearly show the excess ratio stabilizes around the designed excess ratio of 2 , but the response to any change in load current is still inadequate.
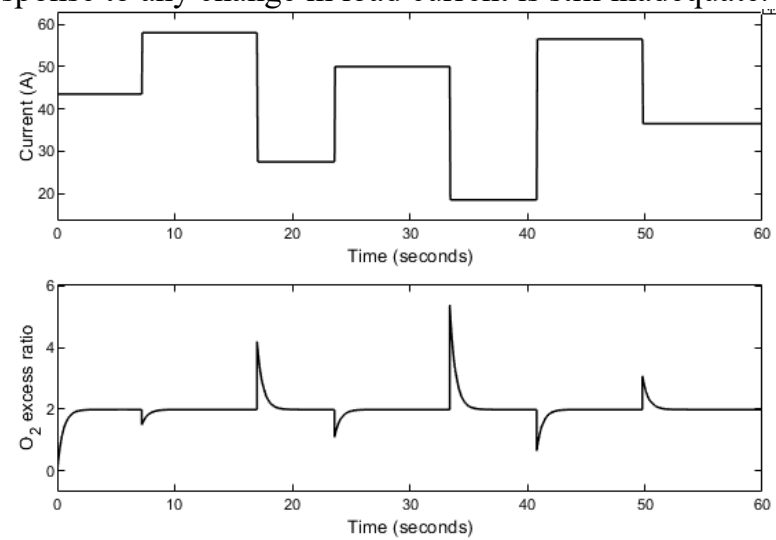

Fig. 7 Oxygen excess ratio using PI controller.

The response of oxygen flow rate to change in load current is relatively slow and takes almost 1.5 s to stabilize as shown in Fig 8. Furthermore, at around 40s when the load changes to $50 \mathrm{~A}$, the excess ratio is seen to drop below one which is unacceptable. This would mean the PEMFC is starved of oxygen.

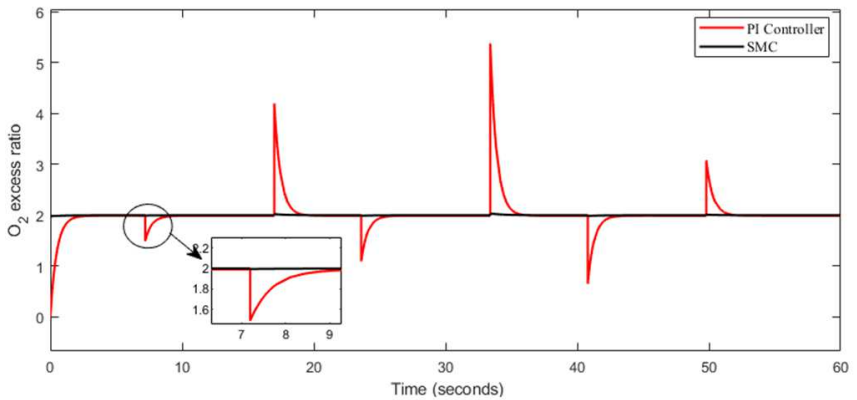

Fig. 8 Magnified view showing the PI response time.

For the SMC the gains were calculated as: $K_{1}=$ 2000, $K_{2}=-1999$ and $K_{3}=1 \times 10^{-7}$. The results of the SMC with the objective of maintaining an oxygen excess ratio of 2 is shown in Fig 9. It can be seen that the excess ratio is reasonably maintained at around 2 with perturbations of less than 0.01 from the reference. This is different from the excess ratio maintained by the PI controller where values below 1 were seen. The Sliding Mode controller performs well to ensure that the oxygen ratio never falls below 1 to avoid oxygen starvation. This control topology, therefore, achieves the objective even on a simplified PEMFC model. The proper control of the excess ratio ensures smooth power output and long life of the individual cells in the PEMFC.
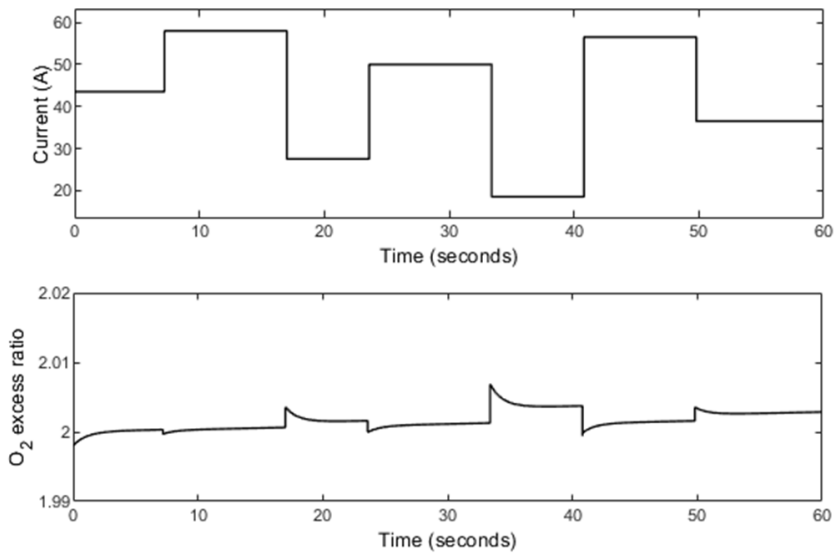

Fig. 9 Oxygen excess ratio controlled using SMC.

The oxygen flow rate response is slower when using the traditional PI control with feedback, as shown in Fig 10. This is one of the reasons why the oxygen excess ratio is difficult to maintain using simple PI control. In an actual system, more delays are anticipated as the oxygen is supplied using an axial fan. Unlike large compressor driven systems, there is no storage of air in a supply manifold, and hence the response of the oxygen supply subsystem is much more critical.

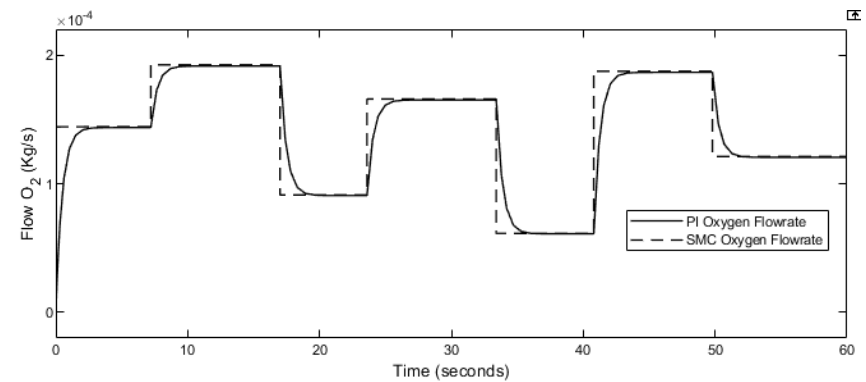

Fig. 10 Flow rate of oxygen using PI and SMC control.

Given the simplified model of the PEMFC, greater emphasis needs to be placed on the controller to account for the loss of details in model simplification. As seen in Fig 11, the SMC controller is resilient to changes in parameters as well unlike the PI controller. In Fig 11 , the $k_{c, o u t}$ was increased by $60 \%$ and the SMC controller still maintained the oxygen excess ratio at 2 . The SMC controller is especially suited to the nonlinear PEMFC system. Future work will involve modelling of nitrogen, humidity, and temperature and air fan dynamics to further enhance the model with the goal of eventually controlling the PEMFC system using a sliding mode controller. 


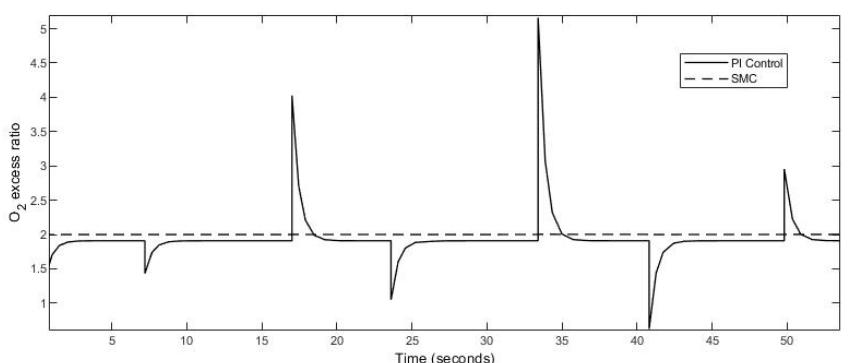

Fig. 11 The SMC controller maintains the excess ratio when parameters change

\section{CONCLUSION}

The paper presents a simplified nonlinear dynamic model which uses just three state variables to estimate the changes in PEMFC system. Results show that with accurate parameter estimations, the model is in agreement with measured results for the Fuel Cell polarization curve. Hydrogen and Oxygen flow rates also correlate with the changing current in a test load profile indicating the suitability of the model for control applications. The simplification of the model allows treating some parameters as constants. While there may be loss of details from the model, it is still useful in early system design of PEMFC or for learning purposes. A Sliding Mode Control (SMC) scheme is applied with the key objective of achieving a constant oxygen excess ratio. The results of the SMC show a greater response of oxygen flow rates compared to traditional PI controllers. The study focused only on the oxygen excess ratio, given its slow dynamics compared to hydrogen flow. Future studies will focus on hydrogen gas and water flow management in the PEMFC.

\section{REFERENCES}

[2] S. Laghrouche, I. Matraji, F. S. Ahmed, S. Jemei, and M. Wack, "Load governor based on constrained extremum seeking for PEM fuel cell oxygen starvation and compressor surge protection," International Journal of Hydrogen Energy, vol. 38, no. 33, pp. 14314-14322, 2013/11/04/ 2013, doi: https://doi.org/10.1016/j.ijhydene.2013.08.109.

[3] W.-c. Yang, B. Bates, N. Fletcher, and R. Pow, "Control challenges and methodologies in fuel cell vehicle development," SAE Technical Paper, 1998.
J. Chen, Z. Liu, F. Wang, Q. Ouyang, and H. Su, "Optimal Oxygen Excess Ratio Control for PEM Fuel Cells," IEEE

Transactions on Control Systems Technology, vol. 26, no. 5, pp. 1711-1721, 2018, doi: 10.1109/TCST.2017.2723343.

[5] M. A. Danzer, J. Wilhelm, H. Aschemann, and E. P. Hofer, "Model-based control of cathode pressure and oxygen excess ratio of a PEM fuel cell system," Journal of Power Sources, vol. 176, no. 2, pp. 515-522, 2008/02/01/ 2008, doi: https://doi.org/10.1016/j.jpowsour.2007.08.049.

[6] J. T. Pukrushpan, A. G. Stefanopoulou, and H. Peng, "Modeling and control for PEM fuel cell stack system," in Proceedings of the 2002 American Control Conference (IEEE Cat. No. CH37301), 2002, vol. 4: IEEE, pp. 3117-3122.

[7] C. Lu-Ying, B. Diong, and R. S. Gemmen, "An improved smallsignal model of the dynamic behavior of PEM fuel cells," IEEE Transactions on Industry Applications, vol. 40, no. 4, pp. 970977, 2004, doi: 10.1109/TIA.2004.830746.

[8] G. Marsala, M. Pucci, G. Vitale, M. Cirrincione, and A. Miraoui, "A prototype of a fuel cell PEM emulator based on a buck converter," Applied Energy, vol. 86, no. 10, pp. 2192-2203, 2009/10/01/ 2009, https://doi.org/10.1016/j.apenergy.2008.12.028.

[9] W. Daud, R. Rosli, E. Majlan, S. Hamid, R. Mohamed, and T. Husaini, "PEM fuel cell system control: A review," Renewable Energy, vol. 113, pp. 620-638, 2017.

[10] C. H. Woo and J. B. Benziger, "PEM fuel cell current regulation by fuel feed control," Chemical Engineering Science, vol. 62, no. 4, pp. 957-968, 2007/02/01/ 2007, doi: https://doi.org/10.1016/j.ces.2006.10.027.

[11] M. Serra, J. Aguado, X. Ansede, and J. Riera, "Controllability analysis of decentralised linear controllers for polymeric fuel cells," Journal of Power Sources, vol. 151, pp. 93-102, 2005.

[12] V. Utkin, "Variable structure systems with sliding modes," IEEE Transactions on Automatic control, vol. 22, no. 2, pp. 212-222, 1977.

[13] C.-T. Chen and S.-T. Peng, "A sliding mode control scheme for non-minimum phase non-linear uncertain input-delay chemical processes," Journal of Process Control, vol. 16, no. 1, pp. 37-51, 2006.

[14] K. R. Ram, K. Naidu, R. Kumar, M. Cirrincione, and A. Mohammadi, "Model comparison and parameter estimation of polymer exchange membrane (PEM) fuel cell based on nonlinear least squares method," in 2019 International Aegean Conference on Electrical Machines and Power Electronics (ACEMP) \& 2019 International Conference on Optimization of Electrical and Electronic Equipment (OPTIM), 2019: IEEE, pp. 500-505. 